\title{
Social Robots: Their History and What They Can Do for Us
}

\author{
Nadia Magnenat Thalmann
}

\begin{abstract}
From antiquity to today, some scientists, writers, and artists are passionate about representing humans not only as beautiful statues but as automatons that can perform actions. Already in ancient Greece, we can find some examples of automatons that replaced servants. In this chapter, we go through the development of automatons until the social robots of today. We describe two examples of social robots, EVA and Nadine, that we have been working with. We present two case studies, one in an insurance company and the other one in an elderly home. We also mention the limits of the use of social robots, their dangers, and the importance to control their actions through ethical committees.
\end{abstract}

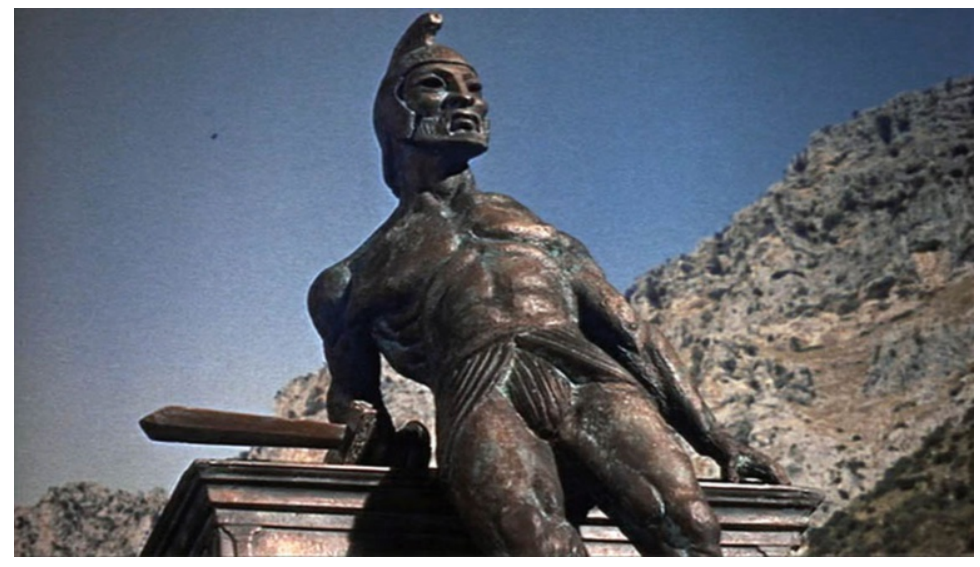

Talos, the giant automaton from Greece

\footnotetext{
N. M. Thalmann (四)

MIRALab, University of Geneva, Geneva, Switzerland

e-mail: Nadia.thalmann@unige.ch
} 


\section{History of Human Robotics}

Fascination for automation is neither new nor modern. Living side by side with automated, mechanical beings which look like us and can do fantastic things or protect us is one of mankind's oldest dreams. In 400 BC, Greek mythology already featured the tale of Talos, a 10-m giant automaton made of bronze. He was brought to life by the gods to ward off pirates and invaders and to keep watch to protect the island. Sometime later, in $250 \mathrm{BC}$, a human-like automatic device in the form of a maid, holding a jug of wine in her right hand was made. When one placed a cup in the palm of the automaton's left hand, it automatically poured wine initially and then poured water into the cup, mixing it when desired (Fig. 1).

This automatic maid can be seen in the Museum of ancient Greek Technology in Katalo in Greece.

Leonardo Da Vinci, in the late fifteenth century, did technical drawings that were found recently. These drawings have allowed the creation of a mechanical humanoid automaton, a robotic knight which is capable of independent motion. It could stand, sit, raise its visor, and maneuver its arms independently (Fig. 2). It was fully done according to Leonardo Da Vinci's drawings and is fully working.

Later, a marvel of automatons has been produced and shown in 1775 in London. Spectators could see three animated human figures made by Pierre and Henri Louis Droz, from Switzerland. These automatons were autonomously able to write, to

Fig. 1 Automatic maid, done by Philon

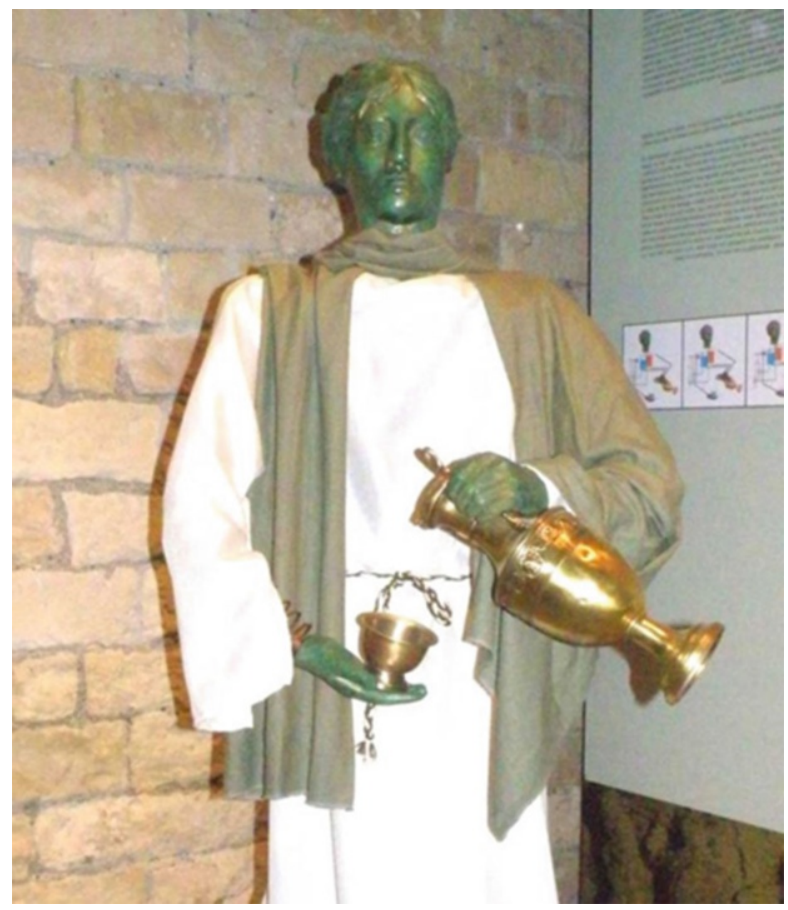




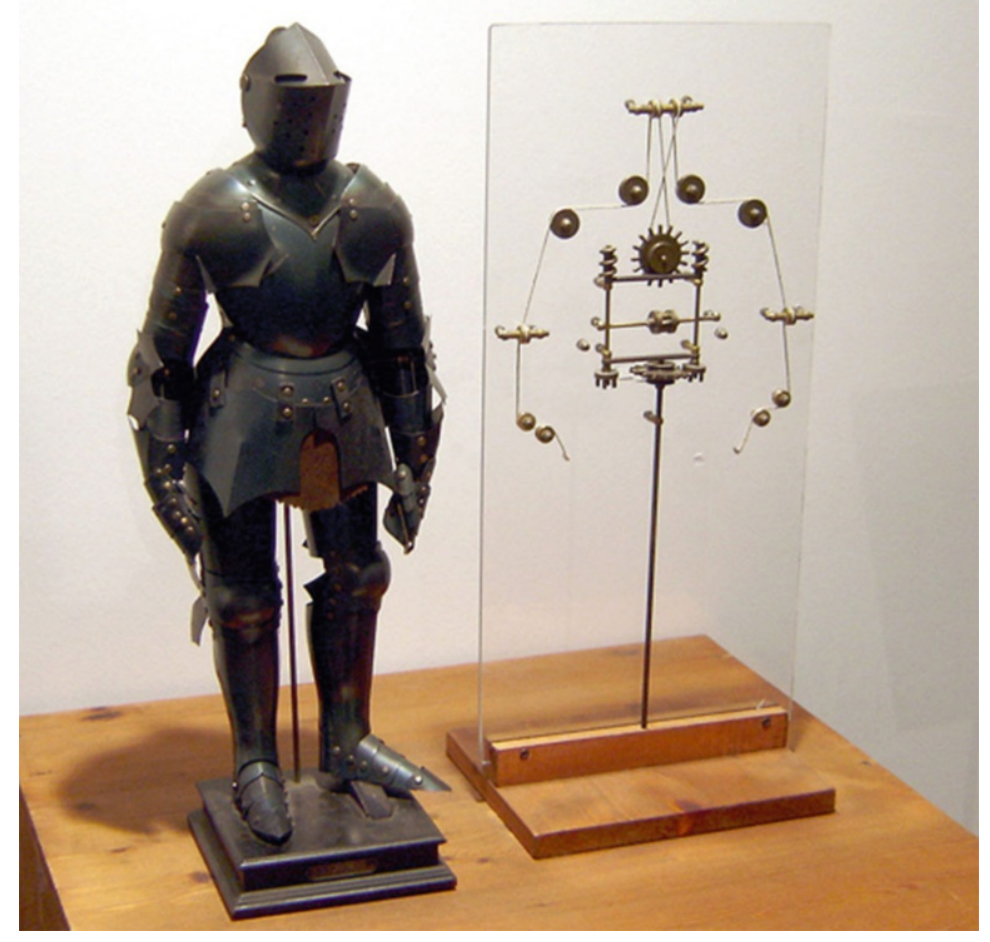

Fig. 2 Robotic knight

draw, or to play a keyboard instrument. This exhibition at Covent Garden generated a lot of questions among famous writers. Some imaginary plays as, for example, "Les Contes d'Hoffmann" were produced. Hoffmann is the author of one of the masterpieces "The Sandman." In this piece, he tells the story of a young man who fell in love with the automaton Olympia. It has been followed by Jacques Offenbach's opera, "Les Contes d'Hoffmann." These imaginary masterpieces, even if they demonstrate no new technical real automaton, show how someone can be duped by the beauty and actions of an automaton (Fig. 3).

The development of automations has created other philosophical interests. In the eighteenth century, French philosopher Denis Diderot reflected on the possibility of modelling intelligence. In his Pensées Philosophiques, he wrote "If they find a parrot who could answer everything, I will claim it to be an intelligent being without hesitation." As early as the eighteenth century, there was already a lot of discussion about what intelligence is and whether it could be modelled to be integrated within machines. 
Fig. 3 Swiss automaton

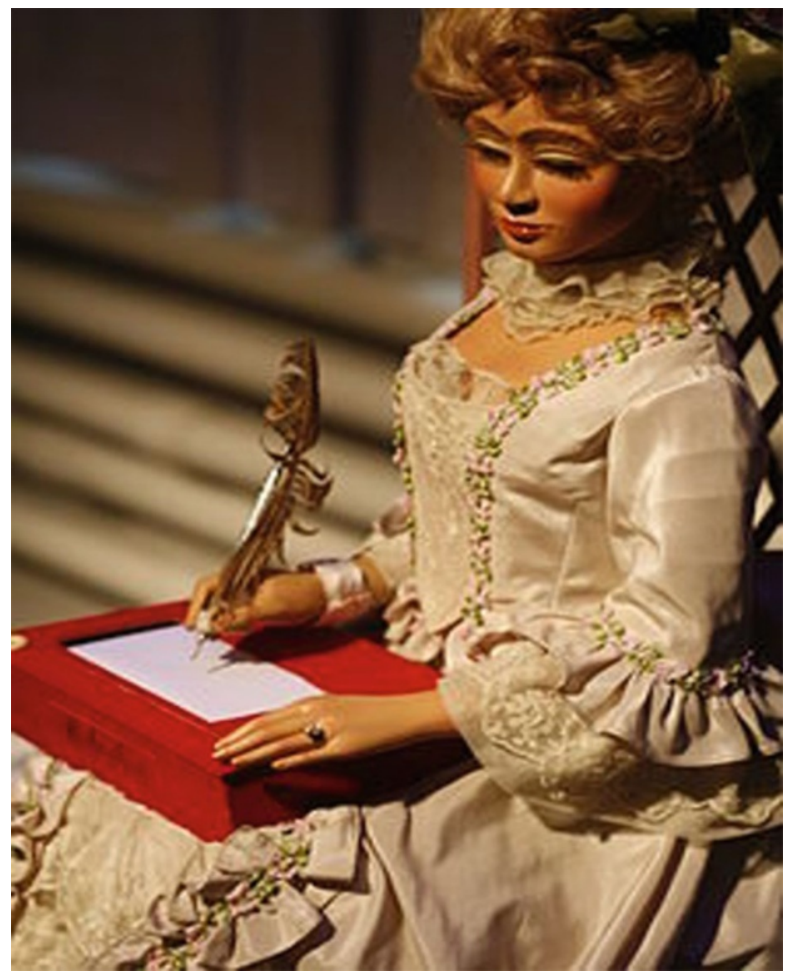

In 1950, Alan Turing developed the Turing Test to test a machine's ability to exhibit intelligent behavior equivalent to, or indistinguishable from, that of a human. ${ }^{1}$ However, it was soon felt that the Turing Test was not sufficient. As the notions of social and emotional intelligence theory grew in the 1980s and 1990s, human intelligence was understood not only as an ability to answer logical questions based on logical reasoning, but rather as an ability to take account of one's environment, the real world, social interactions, and emotions, and this is something the Turing Test could not measure. This paved the way for new technical developments towards intelligent social robots.

Alongside the evolution in social sciences, computer science, too, developed over time. Sixty years ago, computers were very large and were very limited. Today, they are much smaller, much faster, and much more powerful and offer incredible possibilities of interfacing with people through sensors and actuators. We have now many software and hardware tools which can capture, understand, and analyze a lot of signals and meanings. We can capture speech, sounds, gestures, shapes, etc. Through the emergence of big data and machine learning, we can analyze new data, find correspondence, and predict future patterns.

\footnotetext{
${ }^{1}$ https://en.wikipedia.org/wiki/Turing_test
} 
Fig. 4 EVA interacting with a user

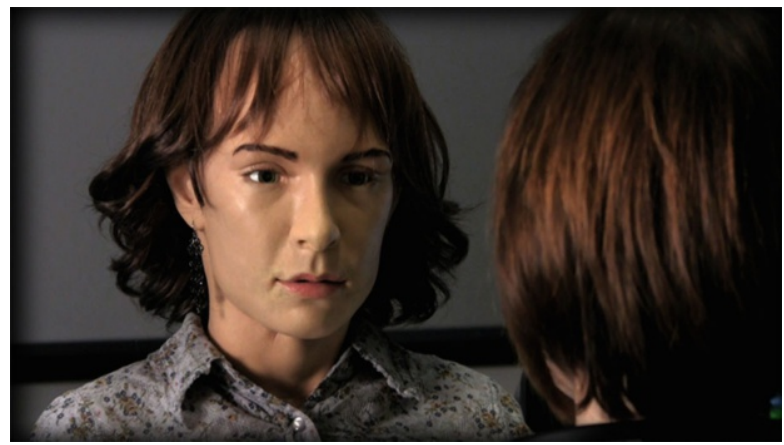

\section{The Challenges of Becoming Social}

A social robot is defined as "an autonomous entity that interacts and communicates with humans or other autonomous physical agents by following social behaviours and rules attached to its role." "Social robots interact with people in social contexts. Therefore, they must understand the social context, i.e., understand users' behaviors and emotions, and respond with the appropriate gestures, facial expressions, and gaze. The challenge is to provide algorithms to sense, analyze situations and intentions, and make appropriate decisions.

Our lab's first social robot project in Switzerland was EVA (2008-2012), a robotic tutor (Fig. 4). The overall goal of this project was to develop a long-term social interaction framework with a human-like robot or virtual human, modelling emotions, episodic memory, and expressive behavior.

EVA can interact with users by recognizing and remembering their names and can understand users' emotional states through facial expression recognition and speech. Based on user input and its personality model, EVA produces appropriate emotional responses and keeps information on the long-term interpersonal relationships (Kasap and Magnenat Thalmann 2012). EVA played a role as an actor with real actors in the Roten Fabrik Theater at Zurich.

Taking this one step further, in 2013, we started in NTU in Singapore working on Nadine, a socially intelligent robot with a strong human-likeness, a natural-looking skin and hair, and realistic hands and body. One of our main motivation over time is not only to produce a technical innovation but also to contribute to art. Nadine has been recognized as a beautiful living sculpture, a piece of expressive art with a very human-computer natural interface. ${ }^{3}$ We consider this kind of realistic robots as the next step in the making of living sculptures. Nadine is equipped with a 3D camera and a microphone. It can recognize people, gestures, and clues of social situations of emotion and behavior as well as speech, which enables it to understand social situations. Nadine has an emotional module, a memory, and a social attention

\footnotetext{
${ }^{2}$ https://en.wikipedia.org/wiki/Social_robot

${ }^{3}$ https://en.wikipedia.org/wiki/Nadine_Social_Robot
} 


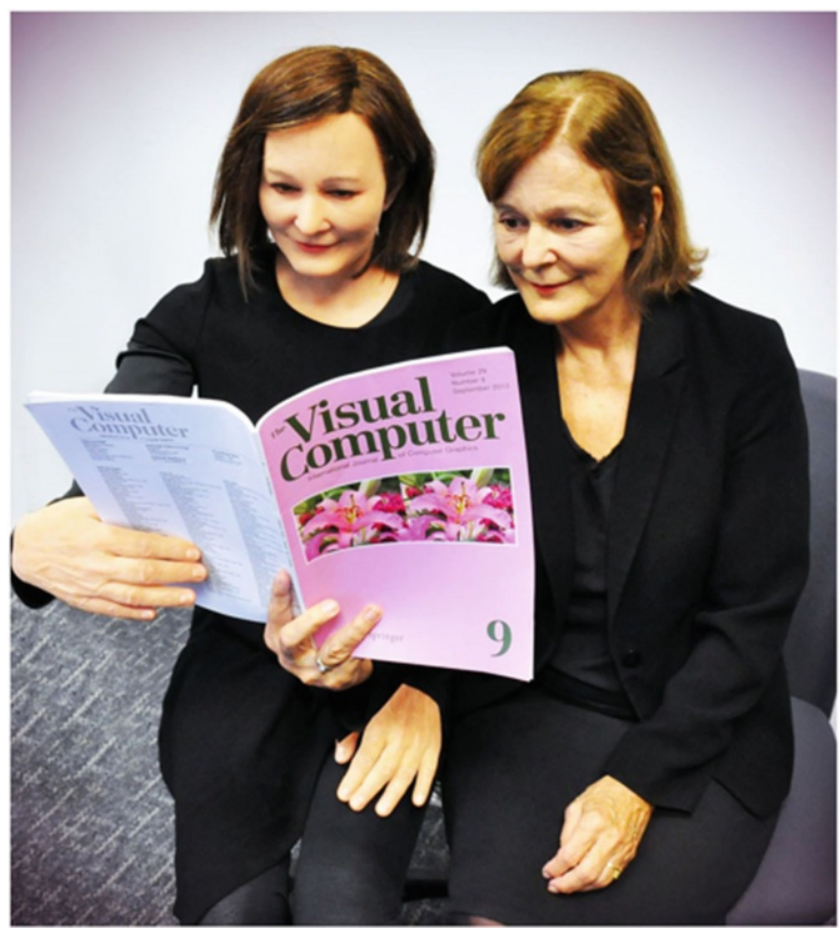

Fig. 5 Nadine and Nadia

model as well as a chatbot, which means that depending on the input, it will generate the appropriate emotional response and remember interactions. Nadine's controllers control lip synchronization and its gaze and enable Nadine to adapt its facial expressions to basic emotions (Fig. 5). It has a personality, mood, and emotion model, and depending on its relationship with a user, its response will vary and adapt to each situation.

\section{Case Studies in an Insurance Company and in an Elderly Home}

We have conducted a study with Nadine humanoid social robot as a customer service agent in an insurance company in Singapore alongside human employees. Nadine was accessible to the public, and the customer could ask any question relative to the insurance. As a service customer agent, Nadine was able to answer customer queries and maintain a courteous, professional behavior during interaction. Our objective was to study if a robot could handle real social situations, if customers were willing to interact with human-like robots, and to study the usefulness of a humanoid robot 


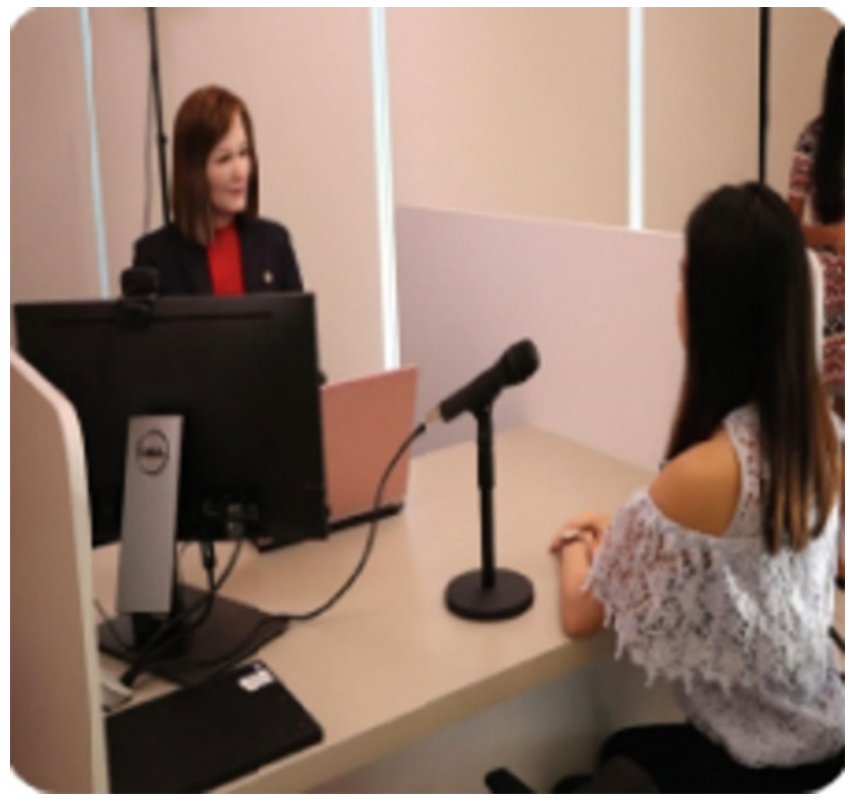

Fig. 6 Nadine at AIA Insurance

in an insurance environment. For customer queries, the company had provided several FAQs from their customer interactions. A separate chatbot was trained based on these FAQs and integrated into Nadine, which allowed her to handle customer queries.

The appearance of the robot played a vital role in the way customers perceived the robot. The company trained at the same time another robot named Pepper. The study showed clearly that Nadine was preferred as it had a human appearance and was more trustable as a customer agent than the robot Pepper that had a more robotic appearance. Pepper was considered as a fancy robot to play with but not for answering and informing people how to get an insurance policy. Nadine was able to provide a better customer interaction experience (Fig. 6).

With the combined effect of increasing life spans, reduced mortality rates, and declining birth rates, the world is growing older. Therefore, the need for social or assistive robots will become more pressing than ever before. A report published by the World Economic Forum states that "Current projections already estimate that by 2050, Japan will have 72 dependent people over 65 for every 100 workers. For Spain, Italy, and Germany, these numbers range between $60 \%$ and $70 \%$." In such contexts, social robots will become a necessary and vital ally in managing our ageing society in a sustainable way.

We have just completed a 6-month study in Bright Hill Evergreen Home, an elderly home in Singapore where Nadine has played bingo with the elderly and interacted with them upon their demand. The data analysis is very positive. Patients largely prefer having a social human-like robot to play bingo with them instead of a 
therapist who has little time. Nadine could repeat the numbers, show results on several screens, and take the time to congratulate people. Patients also highly appreciated the natural human-like beauty of Nadine. ${ }^{4}$

\section{Ethical Issues of Social Robots}

Most researchers are developing robots for a better humanity, and the examples cited above fall into this category. Others fabricate killer robots, dominant robots, and bio robots to use them against humans for profits or for hateful purposes. Fortunately, researchers from diverse areas are beginning to formulate together ethical questions about the use of robotic technology and its implementation in societies. A very important report on the ethics of robotics has been published by the World Commission of the Ethics of Scientific Knowledge and Technology in 2017. ${ }^{5}$ Important Ethical committees are taken place as IEEE and $\mathrm{ACM}^{6}$ and other professional organizations. More importantly, in research, any project on social robots interacting with humans needs an approval from institutional review boards or ethical committees.

I would like to conclude on the following citation by Aristotle who speculated in his Politics (ca. 322 BC, book 1, part 4) that automata could someday bring human equality:

If, in like manner, the shuttle would weave and the plectrum touch the lyre without a hand to guide them, chief workmen would not want servants, nor masters' slaves.

\section{Reference}

Kasap, Z. and Magnenat Thalmann, N. (2012). Building Long-term Relationships with Virtual and Robotic Characters: The Role of Remembering, The Visual Computer, vol. 28, no. 1, pp. 87-97.

\footnotetext{
${ }^{4}$ Do Elderly enjoy playing Bingo with a humanoid robot? Submitted at Ro-Man 2021 Conference, https://www.dropbox.com/s/fj7qdqm4a01ezhz/NT_Humanoid\%20man\%20vs\%20robots\%20Final $\% 20$ reviewed_May\%203.docx?dl=0

${ }^{5}$ https://unesdoc.unesco.org/ark:/48223/pf0000253952 (report on the ethics of robotics)

${ }^{6} \mathrm{https} / / / \mathrm{dl} . \mathrm{acm} . \mathrm{org} / \mathrm{doi} / 10.1145 / 1167867.1164071$ (Ethical acts in robotics report)
} 
Open Access This chapter is licensed under the terms of the Creative Commons Attribution 4.0 International License (http://creativecommons.org/licenses/by/4.0/), which permits use, sharing, adaptation, distribution and reproduction in any medium or format, as long as you give appropriate credit to the original author(s) and the source, provide a link to the Creative Commons license and indicate if changes were made.

The images or other third party material in this chapter are included in the chapter's Creative Commons license, unless indicated otherwise in a credit line to the material. If material is not included in the chapter's Creative Commons license and your intended use is not permitted by statutory regulation or exceeds the permitted use, you will need to obtain permission directly from the copyright holder. 